\title{
In Vitro Effects of Adenosine on Lymphocytes and Erythrocytes from Horses with Combined Immunodeficiency
}

\author{
Nancy S. Magnuson and Lance E. Perryman, Department of Veterinary \\ Microbiology and Pathology, Washington State University, Pullman, \\ Washington 9.9164
}

\begin{abstract}
A B S T RACT The effect of adenosine on the mitogenic response of peripheral blood lymphocytes (PBL) and on the nucleotide pools of erythrocytes from normal horses, horses heterozygous for the combined immunodeficiency (CID) trait (carriers), and foals with CID was studied. When PBL from normal, carrier, and CID horses were stimulated by phytohemagglutinin (PHA), concanavalin A, or pokeweed mitogen, $\left[{ }^{3} \mathrm{H}\right]-$ thymidine uptake was inhibited by adenosine $(0.1 \mu \mathrm{M}$ to $1.0 \mathrm{mM}$ ) in a dose-dependent manner. Adenosine $(100 \mu \mathrm{M})$ mediated inhibition of $\left[{ }^{3} \mathrm{H}\right]$ thymidine uptake was prevented in both normal and carrier horse PBL by incubation with uridine. Uridine had no sparing effect on PBL from horses with CID.
\end{abstract}

Differences were detected between human and horse PBL in response to adenosine and erythro-9-(2hyroxy-3-nonyl) adenine (EHNA), a competitive inhibitor of adenosine deaminase. In the first assay, mitogen-stimulated PBL from horses were more sensitive to adenosine. In the second assay, adenosine was added to PBL cultures at various times after PHA addition. Adenosine inhibited mitogenesis in horse PBL if added within the first $24 \mathrm{~h}$. In human PBL cultures, adenosine inhibited mitogenesis only if added within the first $4 \mathrm{~h}$. The third assay measured capacity of PHA-stimulated human and horse lymphocytes to escape inhibition by adenosine or EHNA. At the end of a 72-h culture period, horse PBL were still inhibited by adenosine and EHNA, but human PBL were not. EHNA and adenosine together caused synergistic inhibition of mitogenesis in both human and horse PBL. With prolonged incubation (72 h), synergistic inhibition was detected only in horse PBL.

With high-pressure liquid chromatography, nucleotide levels in erythrocytes of normal, carrier, and CID

Received for publication 31 August 1978 and in revised form 26 February 1979. horses were found to be similar. Incubation with adenosine produced a 1.5 - to 2 -fold increase in total adenine nucleotide pools in erythrocytes from all horses. However, these increases were accompanied by alterations in the relative amounts of the nucleotide components. This was seen as a significant decrease in the ATP:(AMP plus ADP plus ATP) ratio and energy charge in erythrocytes from normal horses. In contrast, the ATP:(AMP plus ADP plus ATP) ratio decreased only slightly in erythrocytes from CID horses, whereas no change in the energy charge was detected.

The data from these studies indicate a difference in adenosine metabolism exists between human and horse lymphocytes, and an abnormality may exist in purine metabolism or in an interconnecting pathway in horses with CID.

\section{INTRODUCTION}

Evidence that purine metabolism is important in immune response has been obtained from studies of children with immunodeficiency associated with specific enzyme defects. In 1972, a deficiency of adenosine deaminase $(\mathrm{ADA})^{1}$ was first noted in children with severe combined immunodeficiency, an inherited disorder characterized by marked reduction of functional $B$ and $T$ lymphocytes (1). In 1975, deficiency of nucleotide phosphorylase (NP) was observed in children with a genetic disorder of $\mathrm{T}$ lymphocyte

\footnotetext{
'Abbreviations used in this paper: ADA, adenosine deaminase; CID, combined immunodeficiency; Con A, concanavalin A; EHNA, erythro-9-(hydroxy-3-nonyl) adenine; HBSS, Hanks' balanced salt solution; NP, nucleotide phosphorylase; PBL, peripheral blood lymphocytes; PHA, phytohemagglutinin; PWM, pokeweed mitogen; $t=0$, blood extract theoretically represents the normal erythrocyte nucleotide pool.
} 
function (2). Recently, reduction of a third purine metabolic enzyme, ecto-5'-nucleotidase, has been associated with defective B-lymphocyte activity $(3,4)$.

Although ADA deficiency is observed in less than half of the cases of combined immunodeficiency (CID) in children, the absence of the enzyme appears to be pathogenetically important in the immunodeficiency observed. These children have been shown to have increased levels of adenine, adenosine, deoxyadenosine, adenine nucleotides, and deoxyadenine nucleotides in plasma, urine, lymphocytes, and erythrocytes (5-11). Although the exact biochemical mechanism is not known (12), elevated levels of adenosine and its metabolites are thought to be selective inhibitors for differentiation and function of lymphoid tissue. This hypothesis is based in part on the in vitro observations that lymphoid tissues normally contain high levels of ADA activity (13-15) and that adenosine inhibits mitogen-induced stimulation of normal human lymphocytes (14-21), the growth of human and mouse lymphoblast cell lines (22), and the destruction of tumor cells by specifically sensitized mouse lymphocytes (23). Simultaneous addition of ADA inhibitors and adenosine potentiates these inhibitory effects (17-21, 23). Furthermore, prolonged restoration (6) or transient improvement (24) of lymphocyte function has been achieved by enzyme replacement therapy in ADAdeficient children.

Previous work has shown that ADA and NP activities are normal in tissues from horses with CID $(25,26)$. Nevertheless, some other enzyme defect may influence purine metabolism in horses with CID. Therefore, the biochemical basis for CID in horses is possibly similar to that of CID children that are ADA positive. The fatal autosomal recessive disorder in horses occurs in $\cong 2.5 \%$ of young horses of the Arabian breed (27). There is severe lymphopenia, an absence of lymphocytes with surface immunoglobulin and complement receptors, and in most cases, an absence of phytolectin-responsive (28-32) and mixed lymphocyte culture-responsive lymphocytes (33). Affected horses fail to respond to immunization and do not give delayed type hypersensitivity skin reactions (34). Lymphocytes appear to be the only cells adversely affected as the total number, phagocytic capacity, and surface receptors of neutrophils and monocytes are within normal limits (35). Total hemolytic complement levels are similar to those of normal horses, and CID horses produce secretory component (36).

The purpose of this study was to determine if purine metabolism is altered in horses with CID. Our approach was to evaluate the influence of exogenous adenosine on the mitogenic response of lymphocytes and the nucleotide levels in erythrocytes from horses with CID.

\section{METHODS}

Animals. Horses used in these experiments were obtained from four different groups maintained at Washington State University College of Veterinary Medicine: a herd of 14 normal Shetland ponies, of either sex, 2-12 yr old; a herd of 22 Arabian mares, heterozygous for the CID trait (carriers), 3-15 yr old; 6 Arabian foals with CID; and 2 quarter horses, of either sex, $1 \mathrm{~d}$ old. The diagnosis of CID in Arabian foals was based on previously defined criteria (37). Housing, management, and routine treatment for viral, bacterial, and Pneumocystis carinii infections were performed as described (38). Because it is not possible to differentiate heterozygous carrier Arabian horses from genetically normal Arabian horses by biochemical or functional tests, only mares that had produced offspring confirmed as CID foals were designated as carriers. Shetland ponies were used for normal horse controls because a significant percentage of Arabian horses carry the CID trait (27) and noncarrier Arabian horses and foals could not be selected with certainty. Shetland ponies have been used as normal horse controls in our laboratory for several years. We have detected no differences in immunological responsiveness when compared to other breeds of horses.

Peripheral blood mononuclear cells were periodically available from two Arabian foals with CID, Nos. 1113 and 975 , who were 3 and 8 mo old, respectively, when these experiments were initiated. The cells from CID foal No. 975 responded to mitogen stimulation shortly after transplantation with fetal liver and fetal thymus cells (39). Mitogen responsiveness developed spontaneously in CID foal No. 1113 at $3 \mathrm{wk}$ of age. The typical response of both foals' cells to mitogens was usually between $1 / 10$ and $1 / 3$ normal and continued at this level until death of the foals at 4 and 12 mo of age, respectively.

Human blood was obtained from a group of six healthy male and female volunteers, 25-35 yr old.

Preparation of lymphocytes. Blood samples were collected in sterile heparin. Horse peripheral blood lymphocytes (PBL) were isolated from blood samples as described (34). Leukocyte-rich plasma was diluted $\cong 1: 2$ with Hanks' balanced salt solution (HBSS), layered over a FicollHypaque mixture (Ficoll, Sigma Chemical Co., St. Louis, Mo.; Hypaque, Winthrop Labs., Div. of Sterling Drug, Inc., New York), and centrifuged at $400 \mathrm{~g}$ for $40 \mathrm{~min}$. Human PBL were isolated by diluting whole heparinized blood 1:2 with HBSS, layering over a Ficoll-Hypaque mixture, and centrifuging as described for horse PBL. The cellular band that formed in each case was collected and washed two to five times with HBSS.

Lymphocyte cultures. Horse and human PBL were cultured in microtiter plates (34), each well containing $4 \times 10^{5} \mathrm{PBL}$ in $0.2 \mathrm{ml}$ RPMI-1640 supplemented with $10 \%$ heat-inactivated normal horse serum (40) and $100 \mathrm{U}$ penicillin and $100 \mu \mathrm{g}$ streptomycin $/ \mathrm{ml}$, and incubated in an atmosphere of $5 \% \mathrm{CO}_{2}$ at $37^{\circ} \mathrm{C}$ for the times indicated. Phytohemagglutinin-P (PHA, Difco Laboratories, Detroit, Mich.) concanavalin A (Con A, Sigma Chemical Co.), and pokeweed mitogen (PWM, Grand Island Biological Co., Grand Island, N. Y.) were added to the PBL cultures where indicated to a final concentration of 5,20 , and $1 \mu \mathrm{g} / \mathrm{well}$, respectively. The mitogens were assayed for protein by the Lowry et al. (41) method and were stored at $-70^{\circ} \mathrm{C}$ in small aliquots. $20 \mu \mathrm{l}$ of RPMI 1640 containing $1.0 \mu \mathrm{Ci}$ of $\left[{ }^{3} \mathrm{H}\right]$ thymidine $(6.7 \mathrm{Ci} / \mathrm{mM}$, New England Nuclear, Boston, Mass.) were added for the last 24-h of culture, and the cultures were terminated at the stated time intervals using a microharvester (model M 24V, Biomedical Research and 
Development Labs., Inc., Rockville, Md.). Counts per minute were determined to $2 \%$ accuracy with a Beckman LS 9000 liquid scintillation counter (Beckman Instruments, Inc., Fullerton, Calif.). Each determination was run in triplicate.

Cytotoxicity. Horse PBL were cultured as described, in microtiter plates in the presence of either $1 \mathrm{mM}$ adenosine, $100 \mu \mathrm{M}$ erythro-9-(2-hydroxy-3-nonyl)adenine (EHNA), or $1 \mathrm{mM}$ adenosine and $100 \mu \mathrm{M}$ EHNA, with or without $5 \mu \mathrm{g}$ PHA. Viability was determined by trypan blue dye exclusion after 24,48 , and $72 \mathrm{~h}$ of culturing.

Extraction of erythrocytes for nucleotide samples. Blood samples were collected in sterile heparin. The samples from horses were allowed to sit undisturbed at room temperature for $20 \mathrm{~min}$. At the end of the $20 \mathrm{~min}$, erythrocytes had settled to the bottom of the container allowing removal of the leukocyte- and platelet-rich plasma. This procedure removed between 70 and $90 \%$ of the nucleated cells. Erythrocytes were then washed three times with sterile HBSS. Aliquots of $3.5 \mathrm{ml}$ of packed washed erythrocytes were suspended in $50 \mathrm{ml}$ HBSS with or without $0.5 \mathrm{mM}$ adenosine and incubated at $30^{\circ} \mathrm{C}$ in a shaking water bath for $4 \mathrm{~h}$. Incubation was terminated by washing the cells three times with cold $\left(2^{\circ} \mathrm{C}\right)$ HBSS followed by disruption in a tissue homogenizer with cold $10 \%$ trichloroacetic acid. The supernate was collected, the TCA removed by the two-phase extraction method described by Khym (42), lyophilized, and stored at $-20^{\circ} \mathrm{C}$. For chromatography, the lyophilized extracts were dissolved in $0.4 \mathrm{ml}$ of $0.03 \mathrm{M}$ sodium phosphate buffer, $\mathrm{pH}$ 4.0, and filtered through a $0.22-\mu \mathrm{m}$ Millipore filter (Millipore Corp., Bedford, Mass.). Volumes of $15 \mu \mathrm{l}$, representing $2-3 \times 10^{9}$ cells were analyzed.

High-pressure liquid chromatography. All samples were analyzed on a Du Pont 841 liquid chromatograph (Du Pont, E. I., de Nemours \& Co., Inc., Wilmington, Del.) at ambient temperature, using a Whatman Partisil SAX 10/25 column (Whatman, Inc., Clifton, N. J.), a linear gradient of 0.03-0.75 M sodium phosphate, $\mathrm{pH} 4.0$, and an initial flow rate of $0.8 \mathrm{ml} / \mathrm{min}$. For specific separation of nucleoside monophosphates, the eluting solvent was $0.03 \mathrm{M}$ sodium phosphate, $\mathrm{pH} 4.0$, with a flow rate of $1.0 \mathrm{ml} / \mathrm{min}$. Separation of nucleoside triphosphates was performed with an elution solvent of $0.45 \mathrm{M}$ potassium phosphate, $\mathrm{pH} 3.6$, with a flow rate of $0.8 \mathrm{ml} / \mathrm{min}$.

Peaks were identified by cochromatography with known standards, or with the enzyme peak shift technique as described (43). Peak areas were quantitated by multiplying the peak height times width at half-height.

Chemicals. Standard nucleotides were obtained from Sigma Chemical Co. EHNA (a gift of Gertrude B. Elion, Burroughs Wellcome Co., Triangle Park, N. C.) was first dissolved in distilled water with subsequent dilutions made with RPMI-1640. Adenosine, deoxyadenosine, and uridine were from Sigma Chemical Co. The concentrations of solutions of EHNA $\left(\mathrm{E}_{261 \mathrm{~nm}}\right.$ in $\left.\mathrm{H}_{2} \mathrm{O}=14.2 \times 10^{3}\right)$, adneosine $\left(\mathrm{E}_{260 \mathrm{~nm}}\right.$ in $\mathrm{H}_{2} \mathrm{O}=15.1$ $\left.\times 10^{3}\right)$, and uridine $\left(\mathrm{E}_{262 \mathrm{~nm}}\right.$ in $\left.\mathrm{H}_{2} \mathrm{O}=10.1 \times 10^{3}\right)$ were determined by spectrophotometry at the wavelengths of the absorption maxima.

Statistical analysis. Differences between means were analyzed by Student's $t$ test for either unpaired or paired (paired $t$ test) variables (44).

\section{RESULTS}

Effect of adenosine on the mitogenic response of horse PBL. In cultures of PBL from normal horses, adenosine concentrations $>10 \mu \mathrm{M}$ added simultaneously with $5 \mu \mathrm{g}$ PHA at the start of a 72 -h culture period inhibited uptake of $\left[{ }^{3} \mathrm{H}\right]$ thymidine. Concentrations of adenosine from 0.1 to $10 \mu \mathrm{M}$ had little effect on $\left[{ }^{3} \mathrm{H}\right]$ thymidine incorporation (Fig. $1 a$ ). The adenosine dose-response curves were similar for Con A and PWM (Fig. $\mathrm{l} b$ and $c$ ). The adenosine dose-response curves of PBL from carriers were similar to those of normal horses. Sufficient numbers of mitogen-responsive mononuclear cells for experimental purposes were obtained from two horses with CID. ${ }^{2}$ Although limited availability of cells prevented repetition of all experiments, the results of experiments performed indicated that CID lymphocytes were more sensitive to adenosine than cells from normal horses. Increased inhibition of $\left[{ }^{3} \mathrm{H}\right]$ thymidine uptake by PBL from one CID horse was observed at adenosine concentrations of 0.1-10 $\mu \mathrm{M}$ regardless of the mitogen used to stimulate the lymphocytes (Fig. 1 $(i-c$ ). At $0.1 \mu \mathrm{M}$ adenosine the inhibition was at least 2 SD greater than that observed with both carrier and normal horses for PHA and PWM.

Human PBL cultured under identical conditions also showed inhibiton of $\left[{ }^{3} \mathrm{H}\right]$ thymidine incorporation, but only at adenosine concentrations of $1 \mathrm{mM}$. This adenosine concentration was 10-fold higher than needed for the same level of inhibition found for normal horse PBL (Fig. la-c).

Effect of uridine on adenosine inhibition of $\left[{ }^{3} \mathrm{H}\right]$ thymidine uptake. Uridine appears to reverse the inhibitory action of adenosine on $\left[{ }^{3} \mathrm{H}\right]$ thymidine uptake of cultured lymphocytes $(21,22)$. In our studies, $10 \mu \mathrm{M}$ uridine reversed the inhibition in normal horse PBL incubated with $100 \mu \mathrm{M}$ adenosine (Fig. 2). No difference between PBL from normal and carrier horses could be detected. The uptake of $\left[{ }^{3} \mathrm{H}\right]$ thymidine by Con A-stimulated PBL from both mitogenicresponsive horses with CID was markedly inhibited by $100 \mu \mathrm{M}$ adenosine. However, in comparison to normal and carrier horses, the PBL from CID foals were unaffected by uridine regardless of the concentration used.

Effects of adenosine on PHA-stimulated PBL at 48 and $72 \mathrm{~h}$. Because PBL from humans do not appear to be as sensitive to adenosine after $72 \mathrm{~h}$ exposure as do PBL from horses (Fig. 1), we examined the effects of adenosine on PBL from horses after $48 \mathrm{~h}$ exposure. As seen in Table I, the amount of $\left[{ }^{3} \mathrm{H}\right]$ thymidine uptake in horse PBL was similar at 48 and $72 \mathrm{~h}$ for each of the adenosine concentrations tested. In contrast, previous work has shown that in human PBL cultures the inhibition at $48 \mathrm{~h}$ was no longer detectable after $72 \mathrm{~h}$ except at $1 \mathrm{mM}$ adenosine concentration (20).

${ }^{2}$ The occurrence of phytolectin-responsive lymphocytes in horses with CID is rare. Of the 30 horses with CID we have studied in the past $3 \mathrm{yr}$, only two have developed a detectable mitogenic response. When available, lymphocytes from these two horses were used in these studies. 

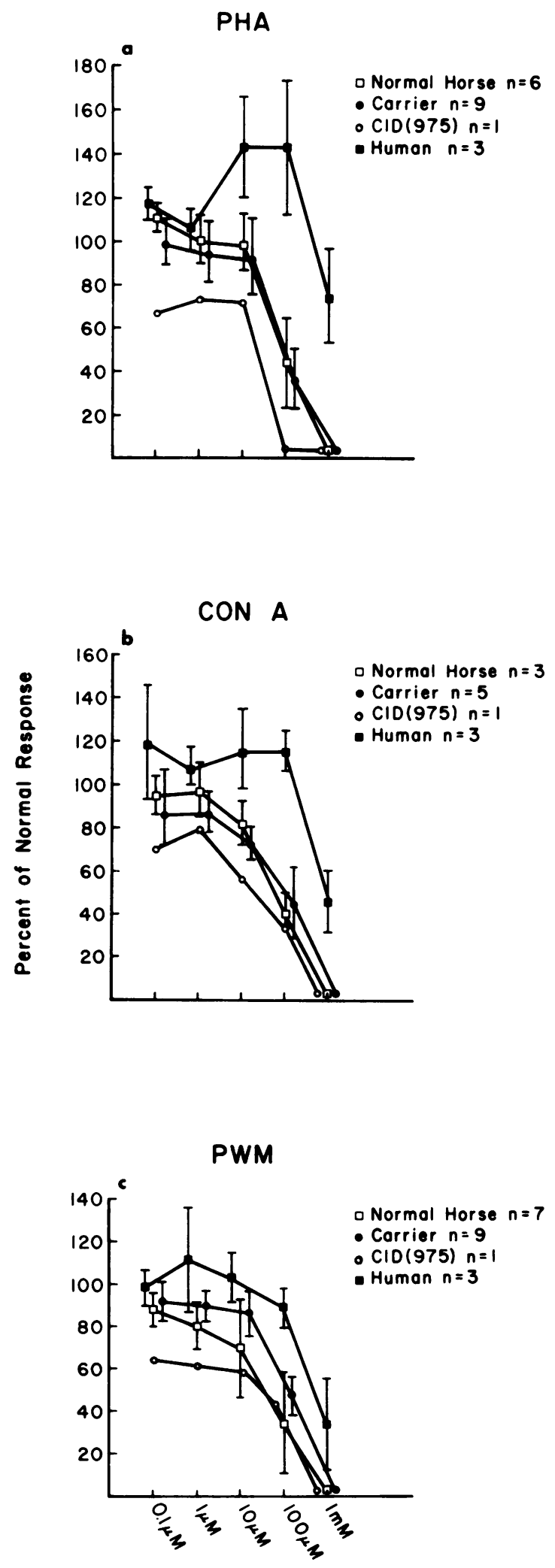

Molarify Adenosine

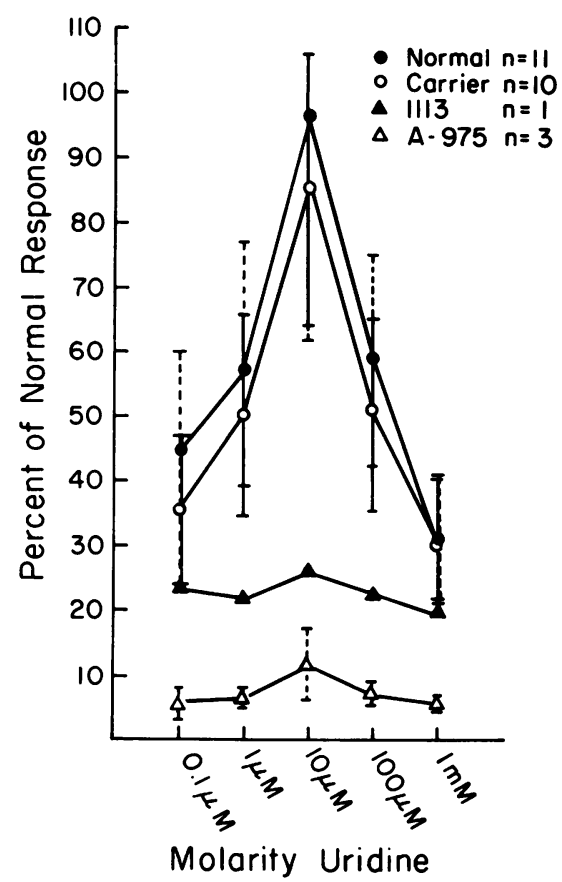

FIgURE 2 Uridine reversal of adenosine inhibition of $\left[{ }^{3} \mathrm{H}\right]$ thymidine uptake in Con A-stimulated lymphocytes. Cells were cultured for $72 \mathrm{~h}$ with the indicated concentrations of uridine together with $100 \mu \mathrm{M}$ adenosine. Results are expressed as mean percentage of radioactivity incorporated by Con A and adenosine-treated PBL divided by the radioactivity incorporated by Con A-treated PBL. The $n$ indicates the number of separate experiments for each group of subjects.

The inhibition observed by others $(20)$ at $48 \mathrm{~h}$ was confirmed by us in a single experiment (Table I).

Time dependence of adenosine addition and adenosine removal from PHA-stimulated PBL. We next examined the effect of adding adenosine at various times after PHA stimulation. All cultures were harvested $72 \mathrm{~h}$ after the addition of mitogen. To obtain similar levels of mitogenic suppression, $1 \mathrm{mM}$ adenosine was added to human PBL cultures while $100 \mu \mathrm{M}$

FIGURE 1 Effect of adenosine on $\left[{ }^{3} \mathrm{H}\right]$ thymidine uptake by mitogen-stimulated PBL. Cells were cultured for $72 \mathrm{~h}$ in media containing $10 \%$ heat-inactivated pooled normal horse serum. Results are expressed as mean percentage of radioactivity incorporated by mitogen- and adenosine-treated PBL divided by the radioactivity incorporated by mitogentreated PBL. The $n$ indicates the number of separate experiments used to calculate the mean $\pm S D$ for each group of subjects. The mean $\pm S D$ uninhibited counts per minutes of $\left[{ }^{3} \mathrm{H}\right]$ thymidine incorporation for the various groups of subjects were as follows. PHA stimulation: human, 121,257 $\pm 43,751$; carrier, 123,430 $\pm 22,399$; CID, 23,046; normal horse, 154,328 $\pm 18,269$; Con A stimulation: human, $67,046 \pm 36,235$; carrier, $106,952 \pm 54,154$; CID , 46,598; normal, 163,452 $\pm 32,471$; PWM stimulation: human, $27,258 \pm 6,336$; carrier, $87,724 \pm 34,545$; CID, 39,867; normal, 121,707 $\pm 7,707$. 
TABLE I

Adenosine Inhibition of PHA-Stimulated PBL Cultures at 48 and $72 \mathrm{~h}$ of Incubation

\begin{tabular}{|c|c|c|c|c|}
\hline \multirow{3}{*}{$\begin{array}{l}\text { Adenosine } \\
\text { concentration }\end{array}$} & \multicolumn{4}{|c|}{ Response of control culture* } \\
\hline & \multicolumn{2}{|c|}{ Horse } & \multicolumn{2}{|c|}{ Human } \\
\hline & $48 \mathrm{~h}$ & $72 \mathrm{~h}$ & $48 \mathrm{~h}$ & $72 \mathrm{~h}$ \\
\hline$\mu M$ & & $\%$ & & \\
\hline 0.1 & $99.9 \pm 12.2(10) \ddagger$ & $98.5 \pm 14.8(11)$ & $139(1)$ & $110.9 \pm 13.9(4)$ \\
\hline 1 & $98.1 \pm 13.3(11)$ & $101.6 \pm 17.6(11)$ & $125(1)$ & $107.2 \pm 9.5$ \\
\hline 10 & $60.7 \pm 29.9(9)$ & $79.1 \pm 19.2(9)$ & $101(1)$ & $148.6 \pm 20.7(4)$ \\
\hline 50 & $12 \quad(1)$ & $18 \quad(1)$ & $48(1)$ & $162 \quad(1)$ \\
\hline 100 & $17.6 \pm 8.1 \quad(11)$ & $19.3 \pm 13.9(11)$ & $39(1)$ & $140.4 \pm 26.4(4)$ \\
\hline $1 \mathrm{mM}$ & $6.6 \pm 4.2$ & $3.8 \pm 6.2$ & $11(1)$ & $66.9 \pm 24.4(4)$ \\
\hline
\end{tabular}

* Percentage of counts per minute incorporated by PHA-stimulated culture alone.

‡ Indicates number of separate experiments included in calculation of mean $\pm \mathrm{SD}$.

adenosine was added to horse PBL cultures. In general, the later adenosine was added to the cultures, the less it inhibited the uptake of $\left[{ }^{3} \mathrm{H}\right]$ thymidine (Fig. 3). DNA synthesis in horse PBL was sensitive to adenosine addition anytime within the first $24 \mathrm{~h}$ of culturing. During this period, maximal mitogen stimulation was always $<50 \%$ of the PHA control. Human PBL were also inhibited to the same degree by adenosine, but only if added during the first $4 \mathrm{~h}$ of incubation.

In a second set of experiments, 72-h cultures of PHA-stimulated PBL were initially incubated in the presence of adenosine. As in the previous experiment, human PBL were cultured with $1 \mathrm{mM}$ adenosine and horse PBL were cultured with $100 \mu \mathrm{M}$ adenosine. Adenosine was removed by washing after varying culture periods. As incubation times with adenosine were increased, $\left[{ }^{3} \mathrm{H}\right]$ thymidine uptake decreased. The responses of human and horse PBL after removal of adenosine were similar (Fig. 4).

Effect of EHNA on horse PBL response to mitogenic stimulation. In Table II, the effect of EHNA on horse PBL stimulated by three different mitogens (PHA, PWM, and Con A) is shown. The level of inhibition appeared to be independent of mitogen type but dependent on the concentration of EHNA. Approxi-

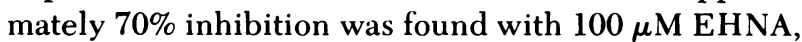
whereas $25 \mu \mathrm{M}$ EHNA gave $\cong 15 \%$ inhibition. As observed with adenosine incubation, no significant change in the inhibition was detected between 48 and $72 \mathrm{~h}$. There was no difference in the response of normal and carrier horses to EHNA.

In another independent set of experiments, the effects of EHNA on PHA-stimulated horse and human PBL were compared. EHNA inhibited $\left[{ }^{3} \mathrm{H}\right]$ thymidine uptake in both human and horse PBL after $48 \mathrm{~h}$ of incubation, but not after $72 \mathrm{~h}$ in human PBL (Table III).

Synergistic effect of adenosine and EHNA on

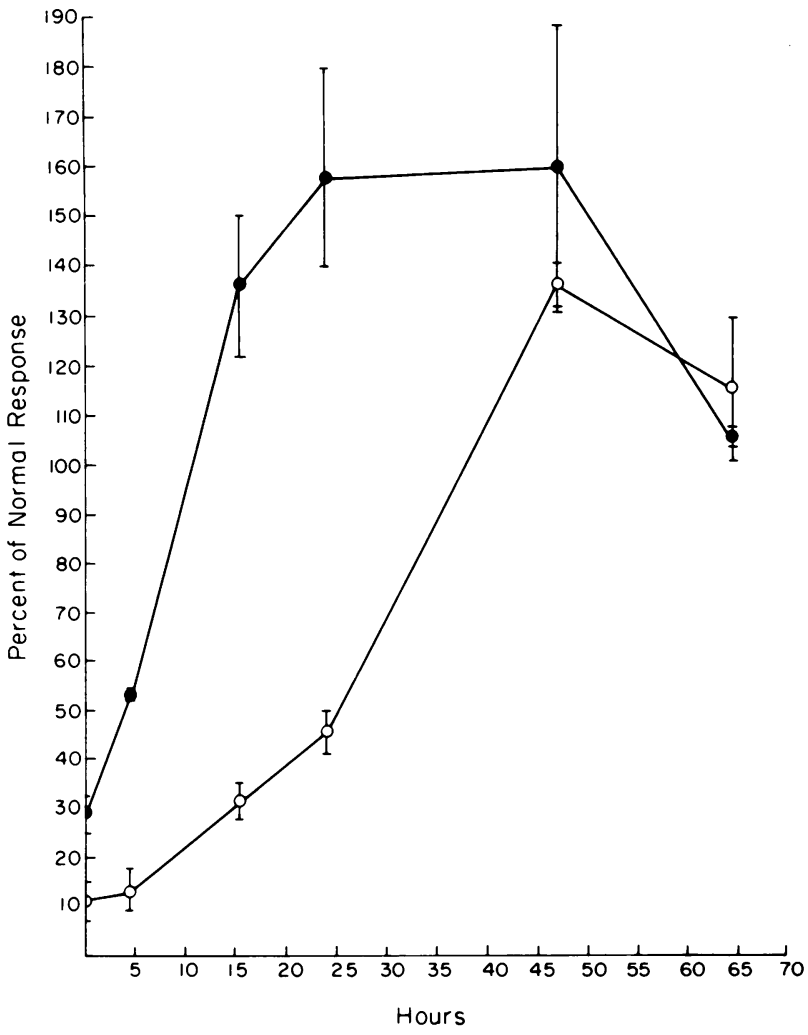

Figure 3 Ability of adenosine to inhibit mitogenesis after initial stimulation with $5 \mu \mathrm{g}$ PHA. Each point indicates the time at which adenosine was added to PHA-stimulated cultures. The incorporation of $\left[{ }^{3} \mathrm{H}\right]$ thymidine over the last $24-\mathrm{h}$ of the 72-h culture period was determined. In horse lymphocyte cultures (O), $100 \mu \mathbf{M}$ adenosine was employed and each point represents the mean $\pm S D$ of four different horses; two horses were carriers and two were normal. In human lymphocyte cultures (O), $1 \mathrm{mM}$ adenosine was employed and each point represents the mean \pm SD of four different human subjects. Results are expressed as mean percentage of radioactivity incorporated by PHA and adenosine-treated PBL divided by the incorporation of PHA-treated PBL. 
inhibition of $\left[{ }^{3} \mathrm{H}\right]$ thymidine uptake. The concentration of $25 \mu \mathrm{M}$ EHNA increased the inhibitory effect of $10 \mu \mathrm{M}$ adenosine from $\cong 27$ to $\cong 56 \%$ at $48 \mathrm{~h}$ (Table III). The increased inhibition was still observed at $72 \mathrm{~h}$. In similar experiments with human PBL, a synergistic effect was observed with $25 \mu \mathrm{M}$ EHNA and $10 \mu \mathrm{M}$ adenosine at $48 \mathrm{~h}$. Unlike the horse, no synergistic effect or inhibition was observed at $72 \mathrm{~h}$.

The toxicity of adenosine was determined by trypan blue dye exclusion. When $1 \mathrm{mM}$ adenosine, $100 \mu \mathrm{M}$ EHNA, $5 \mu \mathrm{g}$ PHA, or a combination of any of these was incubated with normal horse PBL, no decrease in viability was detected after 24 or $48 \mathrm{~h}$ of incubation. A small but significant decrease in viability was only detected after $72 \mathrm{~h}$ of culturing with adenosine $(11.2 \%)$ in the presence of PHA $(P<0.001)$ and with the combination of EHNA and adenosine $(20.4 \%)$ in the presence of PHA $(P<0.01)$.

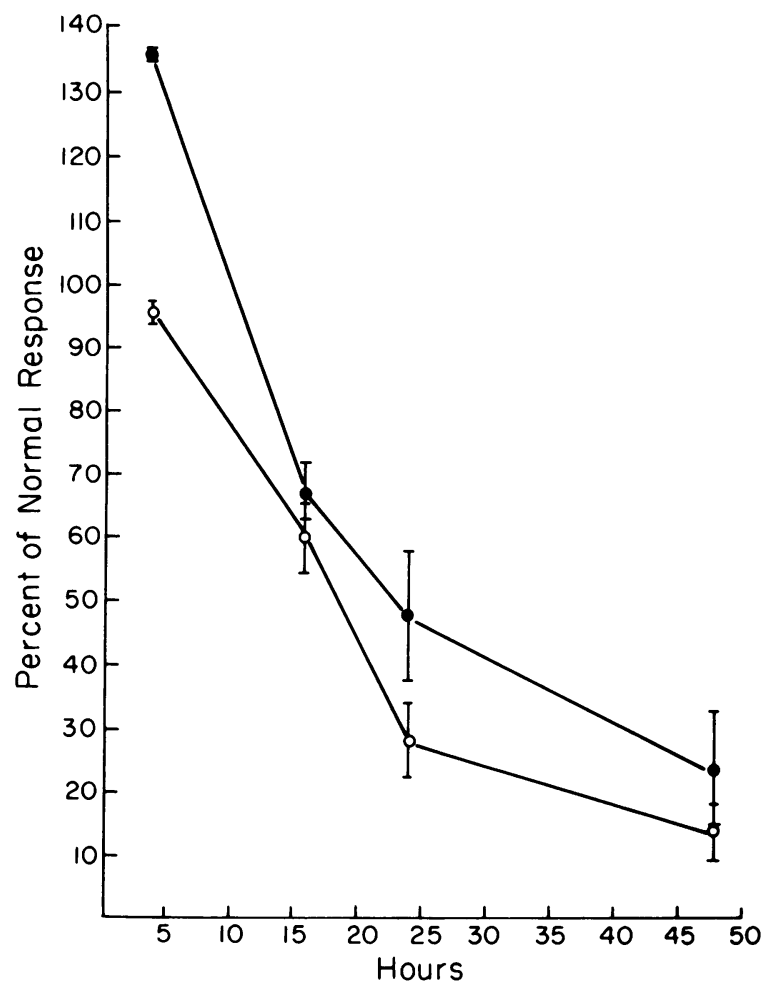

Figure 4 Suppression of PHA-induced incorporation of $\left[{ }^{3} \mathrm{H}\right]$ thymidine by adenosine in horse and human PBL. The number of experiments and adenosine concentrations for horse $(O)$ and human (O) PBL cultures were identical to those described in the legend of Fig. 3. Adenosine and $5 \mu \mathrm{g}$ PHA were added to the PBL at the start of a 72-h culture period. The abscissa indicates the time at which PBL were washed free of adenosine and resuspended in media containing PHA. Culturing was then continued for the remainder of the $72 \mathrm{~h}$ and $\left[{ }^{3} \mathrm{H}\right]$ thymidine was added for the final 24-h of culture. Results are expressed as mean percent radioactivity incorporated by PHA and adenosine-treated PBL divided by the incorporation of PHA-treated PBL.
TABLE II

Effect of EHNA on Horse PBL Response to PHA, Con A, and $P W M$ at 48 and 72 h of Culture

\begin{tabular}{llcc}
\hline & \multicolumn{3}{c}{ Percentage of normal response* } \\
\cline { 2 - 4 } & \multicolumn{1}{c}{ EHNA } & EHNA & EHNA \\
\hline & $100 \mu M$ & $50 \mu M$ & $2.5 \mu M$ \\
48 h & & & \\
PHA & $26.7 \pm 5.8 \pm$ & $57.3 \pm 11.7$ & $84.4 \pm 20.1$ \\
PWM & $31.3 \pm 12.6$ & $72.2 \pm 19.4$ & $98.8 \pm 5.1$ \\
Con A & $18.6 \pm 4.6$ & $48.9 \pm 12.7$ & $68.5 \pm 11.1$ \\
72 h & & & \\
PHA & $30.5 \pm 10.8$ & $78.6 \pm 28.2$ & $84.0 \pm 29.6$ \\
PWM & $45.1 \pm 8.8$ & $72.6 \pm 11.4$ & $102.9 \pm 5.0$ \\
Con A & $38.3 \pm 10.3$ & $58.5 \pm 14.9$ & $86.7 \pm 13.7$ \\
\hline
\end{tabular}

* Percentage of counts per minute of $\left[{ }^{3} \mathrm{H}\right]$ thymidine incorporation without EHNA.

$\$$ Mean \pm SD of four different horses; two horses were carriers and two were normal.

Effect of adenosine on nucleotide pools in erythrocytes from CID horses. Because lymphocytes from CID horses appeared to have increased sensitivity to adenosine, we wished to examine metabolism of adenosine by erythrocytes from horses with CID. Erythrocytes were studied instead of lymphocytes for the following reasons. Adequate numbers of lymphocytes were very difficult to isolate from CID horses because of the severe lymphopenia. In addition, preparations of lymphocytes from CID horses were usually contaminated with significant numbers of neutrophils, monocytes, and large mononuclear cells. ${ }^{3}$ Erythrocytes from horses with CID were available in unlimited quantities and with minor leukocyte contamination. Furthermore, alterations in nucleotides have been previously detected in erythrocytes from children with CID with $(5,8,9)$ and without (45) ADA deficiency. In a typical experiment, erythrocyte nucleotides were extracted from a subject under three different conditions. One extract was obtained from the freshly drawn blood and theoretically represents the normal erythrocyte nucleotide pool. These extracts were designated $t=0$. A second extract was obtained from freshly drawn blood following a 4-h incubation without adenosine and served as the incubation control. A third extract was obtained from the freshly drawn blood following a 4-h incubation with $0.5 \mathrm{mM}$

\footnotetext{
${ }^{3}$ In addition to neutrophil and monocyte contamination, preparations of lymphocytes from CID horses usually contain a significant number of large atypical mononuclear cells that did not morphologically resemble either lymphocytes or monocytes. Because of this apparent heterogeneity which varied from day-to-day, nucleotide analysis of lymphocyte preparations was not pursued.
} 
TABLE III

Synergistic Inhibition of $\left[{ }^{3} \mathrm{H}\right]$ Thymidine Incorporation by Adenosine and EHNA in PHA-Stimulated Lymphocyte Cultures

\begin{tabular}{|c|c|c|c|c|}
\hline & \multicolumn{4}{|c|}{ Percentage of response of control culture* } \\
\hline & \multicolumn{2}{|c|}{$48 \mathrm{~h}$} & \multicolumn{2}{|c|}{$72 \mathrm{~h}$} \\
\hline & Humant & Horse $\S$ & Human & Horse \\
\hline $10 \mu \mathrm{M} \mathrm{A}, "$ PHA & $126.3 \pm 24.9$ & $72.8 \pm 18.5$ & $131.4 \pm 24.2$ & $75.1 \pm 25.4$ \\
\hline $10 \mu \mathrm{M}$ A, PHA, $25 \mu \mathrm{M}$ EHNA & $64.4 \pm 28.7$ & $43.9 \pm 11.8$ & $141.7 \pm 41.5$ & $40.1 \pm 16.1$ \\
\hline $10 \mu \mathrm{M}$ A, PHA, $50 \mu \mathrm{M}$ EHNA & $47.9 \pm 21.0$ & $36.5 \pm 20.3$ & $148.4 \pm 23.1$ & $38.2 \pm 23.9$ \\
\hline $10 \mu \mathrm{M}$ A, PHA, $100 \mu \mathrm{M}$ EHNA & $16.5 \pm 10.4$ & $20.5 \pm 16.6$ & $106.3 \pm 31.8$ & $5.8 \pm 1.7$ \\
\hline PHA, $25 \mu \mathrm{M}$ EHNA & $98.2 \pm 25.3$ & $105.6 \pm 27.4$ & $136.9 \pm 17.3$ & $124.1 \pm 25.4$ \\
\hline PHA, $50 \mu \mathrm{M}$ EHNA & $90.3 \pm 30.6$ & $91.3 \pm 17.1$ & $129.7 \pm 18.7$ & $118.8 \pm 30.8$ \\
\hline PHA, $100 \mu \mathrm{M}$ EHNA & $45.3 \pm 28.4$ & $46.1 \pm 12.9$ & $118.8 \pm 25.8$ & $51.4 \pm 18.7$ \\
\hline
\end{tabular}

* Percentage of counts per minute incorporated by PHA-stimulated culture alone.

$\$$ Represents the means \pm SD of four different humans.

$\S$ Represents the means \pm SD of six different horses; three horses were carriers and three were normal.

"A represents adenosine.

adenosine. All extracts were analyzed by highpressure liquid chromatography.

Fig. 5 is an elution pattern for a standard solution of nucleotides. Nucleotide profiles of erythrocytes from freshly drawn blood $(t=0)$ of normal horses, CID horses, and humans are shown in Fig. $6 a_{1}-c_{1}$. In all chromatograms, ADP and ATP were more easily identified and quantitated than AMP, which usually occurred as a small, poorly resolved peak (Fig. 6a). AMP peaks were clearly identified by (a) cochromatography with AMP standards; (b) performance of the enzymatic peak-shift technique with AMP deaminase (43); and (c) isocratic chromatography of the monophosphate region of the extracts. Total ATP and ADP were greater in human erythrocytes

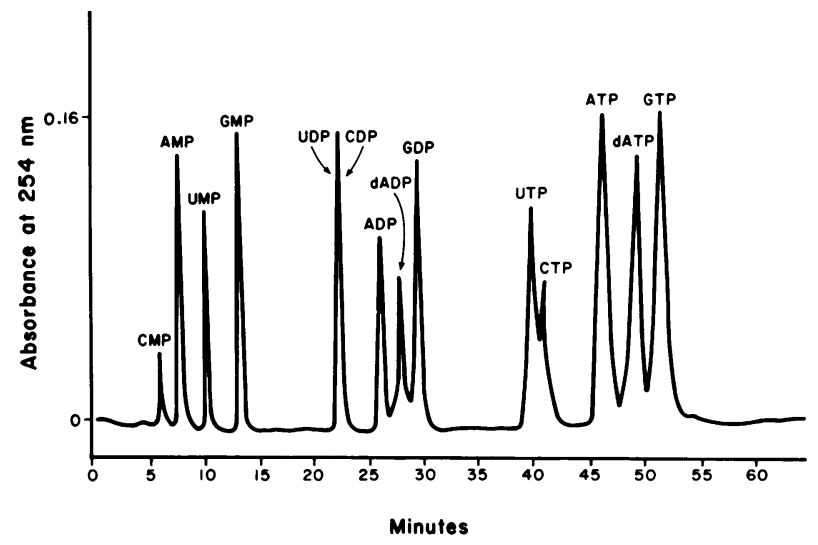

Figure 5 Chromatogram of mono-, di-, and triphosphates of purine and pyrimidine ribosides including the di- and triphosphates of 2'-deoxyadenosine. The nucleotides were eluted from a partisil SAX column with a linear gradient of $0.03-0.75 \mathrm{M}$ sodium phoshate, $\mathrm{pH} 4.0$; flow rate was $1.0 \mathrm{ml} / \mathrm{min}$. than in normal horse erythrocytes as others have also reported (46). Based on comparison of the areas under the peaks with adenine nucleotide standards, human
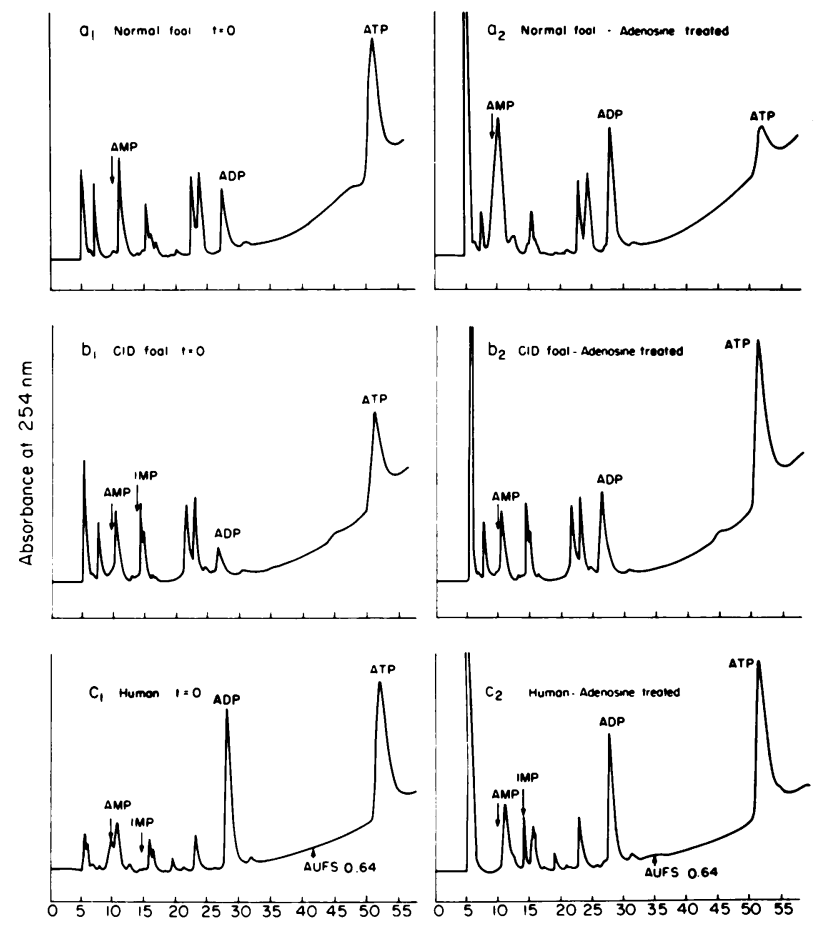

Minutes

Figure 6 Typical chromatograms of nucleotides extracted from erythrocytes. The nucleotides were eluted from a partisil SAX column with a linear gradient of $0.03-0.75 \mathrm{M}$ sodium phosphate, $\mathrm{pH} 4.0$. Flow rate was $0.8 \mathrm{ml} / \mathrm{min}$. Absorption units full scale (AUFS) was 0.32 unless indicated otherwise. 

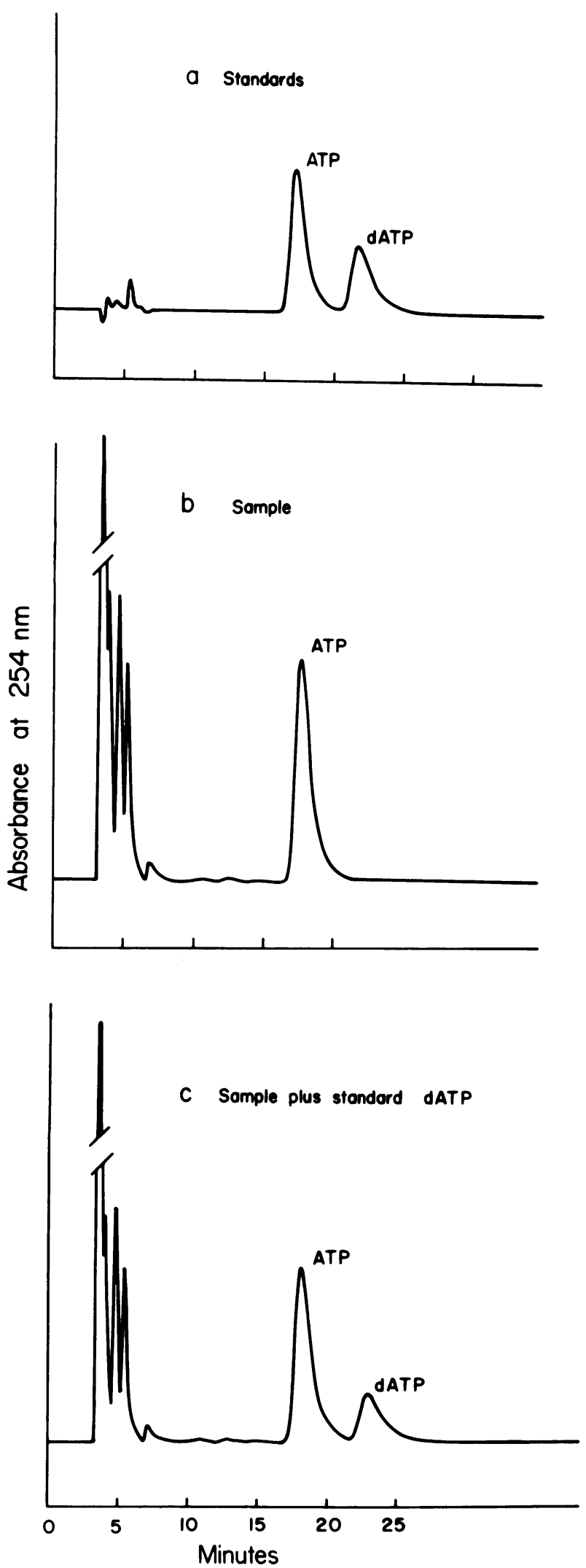

erythrocytes contained $\cong 1,500 \mathrm{nmol}$ of ATP and ADP per milliliter packed cells in agreement with previous reports $(46,47)$. CID and normal horse erythrocytes both contained $\cong 400 \mathrm{nmol}$ of ATP and ADP per milliliter packed cells.

Fig. $6 a_{2}-c_{2}$ shows the nucleotide profiles of erythrocytes after $4 \mathrm{~h}$ of incubation with adenosine. Adenosine incubation produced an increase in adenine nucleotide pools in erythrocytes of both normal and CID horses. The average increase was slightly larger in erythrocytes from horses with CID $(2.0 \pm 0.6)$ than in erythrocytes from normal horses $(1.5 \pm 0.5, P<0.1)$. In general, ATP decreased while ADP and AMP increased in erythrocytes from normal horses (Fig. $6 a_{2}$ ). Increases in both ATP and ADP occurred in erythrocytes from foals with CID (Fig. $6 b_{2}$ ). As demonstrated $(48,49)$, incubation with adenosine did not alter ATP or ADP levels in erythrocytes from humans (Fig. $6 c_{2}$ ).

In agreement with other work, a new peak appeared in the extracts from adenosine-incubated human erythrocytes. It was identified by others as inosine monophosphate $(48,49)$. The new peak in our extracts had a retention time identical to inosine monophosphate. Cochromatography of the erythrocyte extracts with inosine monophosphate increased the size of this peak. No new peak appeared in the nucleotide profile of extracts from normal or CID horses (Fig. $6 a_{2}$ and $b_{2}$ ), indicating inosine monophosphate was not produced as a result of incubation with adenosine.

Because of the increase in ATP in the extracts of erythrocyte from CID foals treated with adenosine, and the observations that 2'-deoxyATP accumulates in erythrocytes from ADA-deficient children with CID $(8,9)$, we checked for the presence of $2^{\prime}$-deoxyATP. Using the linear gradient system routinely employed in our nucleotide pool analysis as described in Figs. 5 and 6 , or the isocratic system as described in Fig. 7, we obtained good separation of 2'-deoxyATP from ATP. We did not observe 2'-deoxyATP in any of our extracts. To be certain that our extraction procedure was not degrading 2 -deoxyATP, we extracted commercial 2'-deoxyATP alone or in the presence of erythrocytes. At least $60 \%$ recovery of the added 2 '-deoxyATP was obtained in all experiments. In addition, following incubation of erythrocytes from normal and CID horses with 2'-deoxyadenosine,

FIGURE 7 Chromatographic separation of ATP and 2'-deoxyATP. The separation was performed on a partisil SAX column with an elution buffer of $0.45 \mathrm{M}$ potassium phosphate, $\mathrm{pH} 3.6$; flow rate was $0.8 \mathrm{ml} / \mathrm{min}$. The chromatograms depict (a) separation of nucleotide standards, $(b)$ separation of nucleotides from adenosine-treated erythrocytes from a CID foal, and $(c)$ the same erythrocyte extract after addition of exogenous 2'-deoxyATP standard. Absorption units full scale is 0.32 . 
approximately half of the adenine nucleotides were found to be in the 2'-deoxy form.

Although not shown in Fig. 5, the same chromatographic conditions separated GTP from 2'-deoxyGTP, with 2'-deoxyGTP eluting after GTP. Increased 2 '-deoxyGTP has been reported in immunodeficiency as a result of NP deficiency (50), however, no increase in either GTP or 2'-deoxyGTP was detected in the nucleotide profiles of extracts from CID horses.

Analysis of the adenine nucleotide pool ratios. Various measures of the adenine nucleotides have been previously used in quantitating the metabolic state of cells (51-53). In our attempt to expose a metabolic difference between normal and CID horse erythrocytes, the adenine nucleotide data gathered from the highpressure liquid chromatograms were examined in two ways. First we analyzed the ATP levels relative to the total adenine nucleotide pool expressed as (AMP plus ADP plus ATP) (Table IV). There was no significant change in ATP:(AMP plus ADP plus ATP) in either normal or CID horse erythrocytes after the 4-h control incubation. There was also no significant difference in the controls ( $t=0$ and incubation control) between normal and CID horses. There was however, a large decrease in the ATP:(AMP plus ADP plus ATP) in erythrocytes from normal horse after $4 \mathrm{~h}$ of incubation with adenosine. The ratio of ATP:(AMP plus ADP plus ATP) for adenosine-treated erythrocytes of normal horses was significantly lower $(P<0.001)$ than the ratio for horses with CID. This indicates that erythrocytes from horses with CID distributed adenine nucleotides differently than normal horse erythrocytes.

A second way of assessing the metabolic state of a cell is to determine the energy charge $(51,53)$, where

$$
\text { energy charge }=\frac{[\mathrm{ATP}]+1 / 2[\mathrm{ADP}]}{[\mathrm{ATP}]+[\mathrm{ADP}]+[\mathrm{AMP}]} .
$$

Table $\mathrm{V}$ shows the calculat d energy charges. There was no significant change in the energy charge in erythrocytes, either from normal or CID horses after the 4-h control incubation. There was also no significant difference in the energy charge for the $t=0$ and incubation control samples between normal and CID horses. A significant decrease in the energy charge was observed in normal horse erythrocytes after incubation with adenosine when compared to the $t=0(P<0.001)$ and incubation control samples $(P<0.01)$. There was, however, no significant change in the energy charge of adenosine-treated erythrocytes from CID horses when compared to $t=0$ and incubation controls. When comparing the adenosine-treated erythrocytes from normal and CID horses the energy charge was significantly lower $(P<0.01)$ for normal horses. Data from age-matched controls and from carriers were similar to that obtained from normal horses (Table VI). Under these experimental conditions, there was no apparent difference between carriers and normal horses.

TABLE IV

Effect of Adenosine on ATP:(AMP plus ADP plus ATP) Ratio of Erythrocytes from Normal Horses and Foals with CID

\begin{tabular}{|c|c|c|c|c|c|c|c|c|}
\hline \multicolumn{4}{|c|}{ Normal horses } & \multicolumn{5}{|c|}{ Foals with CID } \\
\hline \multirow[b]{2}{*}{ Horse } & \multicolumn{3}{|c|}{ Incubation conditions } & \multirow[b]{2}{*}{ Horse } & \multirow[b]{2}{*}{ Age } & \multicolumn{3}{|c|}{ Incubation conditions } \\
\hline & $t=0$ & Control & Adenosine & & & $t=0$ & Control & Adenosine \\
\hline & & & & & $d$ & & & \\
\hline 2 & 0.7 & 0.4 & 0.2 & 1082 & 4 & 0.8 & 0.8 & 0.8 \\
\hline 304 & 0.9 & ND* & 0.4 & & 83 & 0.8 & 0.7 & 0.7 \\
\hline \multirow[t]{3}{*}{328} & 0.9 & 0.8 & 0.2 & 1113 & 1 & 0.8 & 0.8 & 0.7 \\
\hline & 0.7 & 0.7 & 0.3 & & 4 & 0.6 & 0.6 & 0.8 \\
\hline & 0.8 & 0.7 & 0.5 & & 15 & 0.9 & 0.9 & 0.8 \\
\hline \multirow[t]{2}{*}{333} & 0.7 & ND & 0.3 & & 43 & 0.8 & 0.7 & 0.8 \\
\hline & 0.7 & ND & 0.7 & & 46 & 0.9 & 0.8 & 0.3 \\
\hline 338 & 0.9 & 0.8 & 0.5 & & 81 & 0.7 & 0.7 & 0.7 \\
\hline 350 & 0.9 & 0.9 & 0.6 & 1146 & 1 & 0.9 & 0.9 & 0.8 \\
\hline \multirow[t]{2}{*}{376} & 0.8 & ND & 0.3 & & 4 & 0.9 & 0.8 & 0.5 \\
\hline & & & & 1150 & 2 & 0.8 & 0.8 & 0.7 \\
\hline \multirow[t]{4}{*}{ Mean \pm SD } & $0.8 \pm 0.1$ & $0.7 \pm 0.2$ & $0.4 \pm 0.2$ & & $5 \overline{3}$ & 0.9 & 0.9 & 0.7 \\
\hline & & & & 1161 & 21 & 0.7 & & 0.9 \\
\hline & & & & & 39 & 0.9 & 0.9 & 0.7 \\
\hline & & & & Mean $\pm S D$ & & $0.8 \pm 0.1$ & $0.8 \pm 0.1$ & $0.7 \pm 0.1$ \\
\hline
\end{tabular}

* ND, not done. 


\section{TABLE V}

Effect of Adenosine on Energy Charge of Erythrocytes

\begin{tabular}{|c|c|c|c|c|c|c|c|c|}
\hline \multicolumn{4}{|c|}{ Normal horses } & \multicolumn{5}{|c|}{ Foals with CID } \\
\hline \multirow[b]{2}{*}{ Horse } & \multicolumn{3}{|c|}{ Incubation conditions } & \multirow[b]{2}{*}{ Horse } & \multirow[b]{2}{*}{ Age } & \multicolumn{3}{|c|}{ Incubation conditions } \\
\hline & $t=0$ & Control & Adenosine & & & $t=0$ & Control & Adenosine \\
\hline & & & & & $d$ & & & \\
\hline 2 & $0.81^{*}$ & 0.57 & 0.31 & 1082 & 4 & 0.88 & 0.90 & 0.88 \\
\hline 304 & 0.95 & ND $\ddagger$ & 0.54 & & 83 & 0.90 & 0.83 & 0.82 \\
\hline \multirow[t]{3}{*}{328} & 0.93 & 0.89 & 0.71 & 1113 & 1 & 0.90 & 0.89 & 0.82 \\
\hline & 0.90 & 0.80 & 0.66 & & 4 & 0.74 & 0.77 & 0.89 \\
\hline & 0.78 & 0.90 & 0.50 & & 15 & 0.92 & 0.94 & 0.85 \\
\hline 333 & 0.81 & ND & 0.39 & & 43 & 0.90 & 0.84 & 0.89 \\
\hline 333 & 0.84 & ND & 0.77 & & 46 & 0.94 & 0.91 & 0.45 \\
\hline 338 & 0.94 & 0.87 & 0.66 & & 81 & 0.81 & 0.79 & 0.81 \\
\hline 350 & 0.95 & 0.94 & 0.76 & 1146 & 1 & 0.93 & 0.91 & 0.86 \\
\hline \multirow[t]{2}{*}{376} & 0.89 & ND & 0.46 & & 4 & 0.94 & 0.91 & 0.66 \\
\hline & & & & 1150 & 2 & 0.88 & 0.88 & 0.82 \\
\hline \multirow[t]{4}{*}{ Mean \pm SD } & $0.88 \pm 0.06$ & $0.82 \pm 0.13$ & $0.58 \pm 0.16$ & & 53 & 0.96 & 0.92 & 0.81 \\
\hline & & & & 1161 & 21 & 0.84 & ND & 0.92 \\
\hline & & & & & 39 & 0.96 & 0.94 & 0.79 \\
\hline & & & & Mean \pm SD & & $0.89 \pm 0.06$ & $0.87 \pm 0.05$ & $0.81 \pm 0.12$ \\
\hline
\end{tabular}

* Determined by the expression, energy charge $=[$ ATP $]+1 / 2[$ ADP $] /[\mathrm{ATP}]+[\mathrm{ADP}]+[\mathrm{AMP}]$.

$\ddagger$ ND, not done.

\section{DISCUSSION}

Combined immunodeficiency in horses is an important experimental model of that form of severe combined immunodeficiency of children in which ADA activity is normal. Although erythrocytes and plasma of horses lack or have very low levels of ADA $(25,26,40)$, ADA as well as NP is present in other tissues and there is no difference in the levels between normal and
CID horses $(25,26)$. However, because purine metabolic enzyme defects have been associated with immune dysfunction it is possible that additional enzyme abnormalities may occur. The detection of a different enzyme defect in horses with CID could be a significant contribution to understanding the etiology of immune deficiency diseases.

Two observations from these studies with PBL suggest that a defect relating to purine metabolism is

TABLE VI

Comparison of ATP:(AMP plus ADP plus ATP) Ratio and Energy Charge in Erythrocytes before and after Incubation with Adenosine

\begin{tabular}{|c|c|c|c|c|}
\hline \multirow[b]{2}{*}{ Group } & \multicolumn{2}{|c|}{$t=0$} & \multicolumn{2}{|c|}{ Adenosine } \\
\hline & $\begin{array}{l}\text { ATP: } \\
\begin{array}{l}\text { (AMP + ADP } \\
+ \text { ATP })\end{array}\end{array}$ & Energy charge & 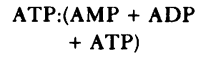 & Energy charge \\
\hline Human, $n=1^{*}$ & 0.7 & 0.84 & 0.8 & 0.89 \\
\hline $\begin{array}{l}\text { Normal horses } \\
\quad(\text { Shetland), } n=10\end{array}$ & $0.8 \pm 0.1$ & $0.88 \pm 0.06$ & $0.4 \pm 0.2$ & $0.58 \pm 0.16$ \\
\hline Carrier horses, $n=2$ & $\begin{array}{l}0.8 \\
0.8\end{array}$ & $\begin{array}{l}0.89 \\
0.85\end{array}$ & $\begin{array}{l}0.3 \\
0.5\end{array}$ & $\begin{array}{l}0.50 \\
0.64\end{array}$ \\
\hline $\begin{array}{l}\text { Age-matched } \\
\text { controls, } \neq n=2\end{array}$ & $\begin{array}{l}0.9 \\
0.9\end{array}$ & $\begin{array}{l}0.93 \\
0.94\end{array}$ & $\begin{array}{l}0.2 \\
0.2\end{array}$ & $\begin{array}{l}0.40 \\
0.32\end{array}$ \\
\hline CID, $n=14$ & $0.8 \pm 0.1$ & $0.89 \pm 0.06$ & $0.7 \pm 0.1$ & $0.81 \pm 0.12$ \\
\hline
\end{tabular}

* $n$, number of determinations.

$\$$ Two quarter horses, each $1 \mathrm{~d}$ old, were used as age-matched controls for the CID horses. 
present in horses with CID. First, when compared to PBL responses of normal horses, PBL responses of horses with CID appear to be more sensitive to adenosine, particularly at low concentrations $(0.1 \mu \mathrm{M})$. In contrast, ADA-deficient lymphocytes from humans have been reported to exhibit little if any increased sensitivity to adenosine $(8,54)$. A greater difference in the dose-response curve at the high adenosine concentrations for CID horses may have been masked in our limited studies because of the large intervals between doses of adenosine. It also cannot be ruled out that the dose-response curve for the CID horse may be a reflection of a change in subpopulations of lymphocytes between affected and normal animals. This is especially important because of recent findings that subpopulations of lymphocytes have different biochemical properties with regards to purine metabolism $(15,55)$. The lack of defined T-lymphocyte markers for horses precluded investigation of this possibility in these studies.

The second observation in our studies with PBL is that addition of uridine did not reverse adenosine inhibition in mitogen-stimulated PBL from horses with CID. However, as others have demonstrated with human PBL (21), uridine did reverse the effects of adenosine in normal horse PBL. These results imply that either an alteration in purine metabolism or a defect in the interrelationship of purine and pyrimidine metabolism is associated with CID in horses. The results, however, do not identify the site of the abnormality or clarify the pathogenic significance of the altered metabolism.

Because the majority of cases of CID are not associated with ADA deficiency, and because four children known to be partially ADA deficient are immunologically normal $(8,56)$, other pathways of purine metabolism, and the role of these pathways on lymphocyte activity should be considered. For these reasons, it was of interest to compare the response of human PBL to exogenous adenosine to that of PBL from normal horses. Unexpectedly, we found horse PBL to be more sensitive to adenosine in assays when comparing adenosine concentration and effects of prolonged incubation. Consistent with other reports, our results from prolonged incubation studies indicated that human PBL either appeared to degrade the exogenous adenosine (20) or escape from the effects of adenosine by some undetermined mechanism. Horse PBL did not appear to have this capacity in spite of the presence of ADA activity (25). Horse and human PBL also responded differently when treated with EHNA, an adenosine deaminase inhibitor. After $72 \mathrm{~h}$ of incubation with EHNA and PHA, DNA synthesis was inhibited only in horse PBL. In previous reports, much lower concentrations of EHNA $(7.8 \mu \mathrm{M})$ have been shown to be effective in inhibiting DNA synthesis in human PBL (20). Others have found that concentra- tions similar to those used here were necessary for inhibition of DNA synthesis $(19,21)$. These differences in effective EHNA concentrations probably result from a variety of factors that may include culture conditions, sensitivity of subjects, and purity of mitogens and inhibitors. Nevertheless, the important result of these experiments is that the two species did respond differently to EHNA under identical culture conditions. This includes PBL responses to PHA stimulation in the presence of both EHNA and adenosine.

Although adenosine and EHNA inhibited $\left[{ }^{3} \mathrm{H}\right]-$ thymidine uptake by mitogen-stimulated horse PBL, these agents were not directly cytotoxic as shown by trypan blue exclusion studies, except in the presence of mitogen for $72 \mathrm{~h}$. Inhibition of $\left[{ }^{3} \mathrm{H}\right]$ thymidine uptake as well as cell death may have resulted from decreased DNA synthesis because of adenosine-induced pyrimidine starvation (57-60) or increased intracellular concentrations of $S$-adenosylhomocysteine preventing essential RNA and DNA methylation (60). Another possible explanation for the increased sensitivity of PBL from horses to adenosine is that adenosine may have an additional site of interaction. Increased adenosine interaction may result because of a higher density or different type of adenosine-specific receptor on the lymphocyte surface. This adenosine-receptor complex may mediate the inhibitory effects of adenosine. Such a mechanism for adenosine inhibition has been recently proposed (61-63).

If a defect in purine metabolism is responsible for CID in horses, the defect must occur at some site other than ADA or NP. Such a defect might be reflected by alterations in the cellular nucleotide pools. Our results showed that the levels of nucleotides in erythrocytes from normal and CID horses at $t=0$ were similar (Fig. 6). The response of erythrocytes to adenosine stress $(0.5 \mathrm{mM})$ was different, however, and the difference was detected by changes in the distribution of adenine nucleotides. The new distribution resulted in a significant decrease in the high energy components (energy charge) in the normal horse erythrocytes. The drop in the energy charge of normal horse erythrocytes to 0.56 with adenosine treatment is taken to be the normal response of horse erythrocytes to high levels of exogenous adenosine. This drop implies that ATP use (break down) exceeds production.

Several investigators have reported elevated levels of 2 -deoxyATP in erythrocytes $(8,9)$ and lymphocytes (10) from ADA-deficient children with CID. Elevated levels of 2 -deoxyadenosine were also found in the urine of an ADA-deficient child with CID (11). It has been proposed that 2 -deoxyadenosine, a substrate of ADA, is potentially toxic in ADA deficiency because it can be converted to 2'-deoxyATP, a potent inhibitor of ribonucleotide reductase $(8,9)$. The absence of detectable levels of 2 -deoxyATP in untreated 
erythrocytes of horses with CID is strong circumstantial evidence that some other mechanism is responsible for CID in horses.

The studies with lymphocytes and erythrocytes described in this paper suggest that there is an enzyme defect in horses with CID involving purine metabolism. We do not know how these observations are related to the immune deficiency or how they reflect metabolic characteristics of other tissues, especially lymphoid tissue, of the same animal. However, the increasing evidence linking purine metabolic defects with immune deficiencies in humans strengthens the possibility that a disorder in purine metabolism is responsible for CID in horses.

\section{ACKNOWLEDGMENTS}

The technical assistance of Ms. Colleen Wong and Ms. Marcia Felton is gratefully acknowledged.

This work was supported in part by U. S. Public Health Service grant HD-08886 from the Institute for Child Health and Human Development, and the Public Service Immunology Training Program, AI 07025.

\section{REFERENCES}

1. Giblett, E. R., J. E. Anderson, F. Cohen, B. Pollara, and H. J. Meuwissen. 1972. Adenosine-deaminase deficiency in two patients with severely impaired cellular immunity. Lancet. II: 1067-1069.

2. Giblett, E. R., A. J. Ammann, R. Sandman, D. W. Wara, and L. K. Diamond. 1975. Nucleotide phosphorylase deficiency in a child with severely defective T-cell immunity and normal B-cell immunity. Lancet. II: 1010-1013.

3. Johnson, S. M., G. L. Asheron, R. W. E. Watts, M. E. North, J. Allsop, and A. D. B. Webster. 1977. Lymphocyte purine 5 '-nucleotidase deficiency in primary hypogammaglobulinaemia. Lancet. I: 168-170.

4. Edwards, N. L., D. B. Magilavy, J. T. Cassidy, and I. H. Fox. 1978. Lymphocyte ecto-5' -nucleotidase deficiency in agammaglobulinemia. Science (Wash. D. C.) 201: $628-630$.

5. Mills, G. C., F. C. Schmalstieg, K. B. Trimmer, A. S. Goldman, and R. M. Goldblum. 1976. Purine metabolism in adenosine deaminase deficiency. Proc. Natl. Acad. Sci. U. S. A. 73: 2867-2871.

6. Polmar, S. H., R. C. Stern, A. L. Schwartz, E. M. Wetzler, P. A. Chase, and R. Hirschhorn. 1976. Enzyme replacement therapy for adenosine deaminase deficiency and severe combined immunodeficiency. N. Engl.J. Med. 295: $1337-1343$.

7. Schmalstieg, F. C., J. A. Nelson, G. C. Mills, T. M. Monahan, A. S. Goldman, and R. M. Goldblum. 1977. Increased purine nucleotides in adenosine deaminasedeficient lymphocytes. J. Pediatr. 91: 48-51.

8. Cohen, A., R. Hirschhorn, S. D. Horowitz, A. Rubinstein, S. H. Polmar, R. Hong, and D. W. Martin, Jr. 1978. Deoxyadenosine triphosphate as a potentially toxic metabolite in adenosine deaminase deficiency. Proc. Natl. Acad. Sci. U. S. A. 75: 472-476.

9. Coleman, M. S., J. Donofrio, J. J. Hutton, and L. Hahn. 1978. Identification and quantitation of adenine deoxynucleotides in erythrocytes of a patient with adenosine deaminase deficiency and severe combined immunodeficiency. J. Biol. Chem. 253: 1619-1626.
10. Donofrio, J., Coleman, M. S., Hutton, J. J., Daoud, A., Lampkin, B., and J. Dyminski. 1978. Overproduction of adenine deoxynucleosides and deoxynucleotides in adenosine deaminase deficiency with severe combined immunodeficiency disease. J. Clin. Invest. 62: 884-887.

11. Kuttesch, J. F., F. C. Schmalstieg, and J. A. Nelson. 1978. Analysis of adenosine and other adenine compounds in patients with immunodeficiency diseases. J. Liquid Chromatogr. 1: 97-109.

12. Hirschhorn, R., and D. W. Martin, Jr. 1978. Enzyme defects in immunodeficiency diseases. Springer Seminars in Immunopathology 1: 299-321.

13. Hall, J. G. 1963. Adenosine deaminase activity in lymphoid cells during antibody production. Austral. J. Exp. Biol. Med. Sci. 41: 93-98.

14. Adams, A., and R. A. Harkness. 1976. Adenosine deaminase activity in thymus and other human tissues. Clin. Exp. Immunol. 26: 647-649.

15. Carson, D. A., J. Kaye, and J. E. Seegmiller. 1977. Lymphospecific toxicity in adenosine deaminase deficiency and purine nucleoside phosphorylase deficiency: Possible role of nucleoside kinase(s). Proc. Natl. Acad. Sci. U. S. A. 74: 5677-5681.

16. Smith, J. W., A. L. Steiner, and C. W. Parker. 1971. Human lymphocyte metabolism. Effects of cyclic and noncyclic nucleotides on stimulation by phytohemagglutinin. J. Clin. Invest. 50: 442-448.

17. Hovi, T., J. F. Smyth, A. C. Allison, and S. C. Williams. 1976. Role of adenosine deaminase in lymphocyte proliferation. Clin. Exp. Immunol. 23: 395-403.

18. Snyder, F. F., J. Mendelsohn, and J. E. Seegmiller. 1976. Phytohemagglutinin-stimulated human lymphocytes. $J$. Clin. Invest. 58: 654-666.

19. Fox, I. H., E. C. Keystone, D. D. Cladman, M. Moore, and D. Cane. 1975. Inhibition of mitogen mediated lymphocyte blastogenesis by adenosine. Immunol. Commun. 4: 419-427.

20. Hirschhorn, R., and E. Sela. 1977. Adenosine deaminase and immunodeficiency: an in vitro model. Cell Immunol. 32: $350-360$.

21. Carson, D. A., and J. E. Seegmiller. 1976. Effect of adenosine deaminase inhibition upon human lymphocyte blastogenesis. J. Clin. Invest. 57: 274-282.

22. Green, H., and T. S. Chan. 1973. Pyrimidine starvation induced by adenosine in fibroblasts and lymphoid cells: role of adenosine deaminase. Science (Wash. D. C.). 182: 836-837.

23. Wolberg, G., T. P. Zimmerman, K. Hiemstra, M. Winston, and L. C. Chu. 1975. Adenosine inhibition of lymphocyte-mediated cytolysis: possible role of cyclic adenosine monophosphate. Science (Wash. D. C.). 187: 957-959.

24. Goldblum, R. M:, F. C. Schmalstieg, J. A. Nelson, and G. C. Mills. 1979. Adenosine deaminase (ADA) and other enzyme abnormalities in immune deficiency states. Proceedings of Birth Defects Meeting. In press.

25. McGuire, T. C., B. Pollara, J. J. Moore, and M. J. Poppie. 1976. Evaluation of adenosine deaminase and other purine salvage pathway enzyme in horses with combined immunodeficiency. Infect. Immun. 13: 995-997.

26. Castles, J. J., M. E. Gershwin, W. Saito, A. Ardans, and B. Osburn. 1977. The activity of purine salvage pathway enzymes in murine and horse models of congenital and acquired dysimmunity. Developmental and Comparative Immunology. 1: 165-174.

27. Poppie, M. J., and T. C. McGuire. 1977. Combined immunodeficiency in foals of Arabian breeding: evaluation of mode of inheritance and estimation of prevalence of affected foals and carrier mares and stallions. J. Am. Vet. Med. Assoc. 170: 31-33.

28. McGuire, T. C., and M. J. Poppie. 1973. Hypo- 
gammaglobulinemia and thymic hypoplasia in horses: a primary combined immunodeficiency disorder. Infect. Immun. 8: 272-277.

29. McGuire, T. C., M. J. Poppie, and K. L. Banks. 1974. Combined (B- and T-lymphocyte) immunodeficiency: a fatal genetic disease in Arabian foals. J. Am. Vet. Med. Assoc. 164: 70-76.

30. McGuire, T. C., K. L. Banks, and M. J. Poppie. 1975. Combined immunodeficiency in horses: characterization of the lymphocyte defect. Clin. Immunol. Immunopathol. 3: 555-566.

31. McGuire, T. C., K. L. Banks, and M. J. Poppie. 1976. Combined immunodeficiency (severe), Swiss-type agammaglobulinemia. Am. J. Pathol. 80: 551-554.

32. McGuire, T. C., K. L. Banks, and IV. C. Davis. 1976. Alterations of the thymus and other lymphoid tissue in young horses with combined immunodeficiency. Am.J. Pathol. 84: 39-49.

33. Perryman, L. E., and T. C. McGuire. 1978. Mixed lymphocyte culture responses in combined immunodeficiency of horses. Transplantation (Baltimore). 25: $50-52$.

34. Hodgin, E. C., T. C. McGuire, L. E. Perryman, and B. Grant. 1978. Evaluation of delayed hypersensitivity responses in normal horses and immunodeficient foals. Am. J. Vet. Res. 39: 1161-1167.

35. Banks, K. L., and T. C. McGuire. 1975. Surface receptors on neutrophils and monocytes from immunodeficient and normal horses. Immunology. 28: 581-585.

36. Buening, G. M., L. E. Perryman, and T. C. McGuire. 1978. Immunoglobulins and secretory component in the external secretions of foals with combined immunodeficiency. Infect. Immun. 19: 695-698.

37. Perryman, L. E., T. C. McGuire, and B. J. Hilbert. 1977. Selective immunoglobulin $M$ deficiency in foals. J. Am. Vet. Med. Assoc. 170: 212-215.

38. Perryman, L. E., T. C. McGuire, and T. B. Crawford. 1978. Maintenance of foals with combined immunodeficiency: causes and control of secondary infections. Am. J. Vet. Res. 39: 1043-1047.

39. Perryman, L. E., G. M. Buening, T. C. McGuire, R. L. Torbeck, M. J. Poppie, and G. E. Sale. 1979. Fetal tissue transplantation for immunotherapy of combined immunodeficiency in horses. Clin. Immunol. Immunopathol. 12: 238-251.

40. Schwartz, P. M., C. Shipman, Jr., and J. C. Drach. 1974. Extensively heat-inactivated calf serum: a tissue culture media supplement devoid of adenosine deaminase activity. In vitro (Rockville). 9: 385-386.

41. Lowry, O. H., N. J. Rosenbrough, A. L. Farr, and R. J. Randall. 1951. Protein measurements with the Folin phenol reagent. J. Biol. Chem. 193: 265-275.

42. Khym, J. X. 1975. An analytical system for rapid separation of tissue nucleotides at low pressures on conventional anion exchangers. Clin. Chem. 21: 12451252.

43. Brown, P. R. 1970. The rapid separation of nucleotides in cell extracts using high pressure liquid chromatography. J. Chromatogr. 52: 257-272.

44. Steele, R. G. D., and J. H. Torrie. 1960. Principles and Procedures of Statistics. McGraw-Hill Book Co., New York. 67-87.

45. Goldblum, R. M., F. C. Schmalstieg, A. S. Goldman, J. A. Nelson, and T. M. Monahan. 1976. Abnormal adenine metabolism in severe combined immunodeficiency (SCID) and normal adenosine deaminase (ADA) activity. Pediatr. Res. 10: 387. (Abstr.)

46. Brown, P. R., R. P. Agarwal, J. Gell, and R. E. Parks, Jr. 1972. Nucleotide metabolism in the whole blood of various vertebrates: enzyme levels and the use of high pressure liquid chromatography for the determination of nucleotide patters. Comp. Biochem. Physiol. 43B: 891-904.

47. Buetler, E. 1975. Red Cell Metabolism: a manual of biochemical methods. Grune \& Stratton, New York, Inc. 149.

48. Parks, Jr., R. E., G. W. Crabtree, C. M. Kong, R. P. Agarwal, K. C. Agarwal, and E. M. Scholar. 1975. Incorporation of analog purine nucleosides into formed elements of human blood: erythrocytes, platelets, and lymphocytes. Ann. N. Y. Acad. Sci. 255: 412-434.

49. Agarwal, R. P., G. IV. Crabtree, R. E. Parks, Jr., J. A. Nelson, R. Keightley, R. Parkman, F. S. Rosen, R. C. Stern, and S. H. Polmar. 1976. Purine nucleoside metabolism in the erythrocytes of patients with adenosine deaminase deficiency and severe combined immunodeficiency. J. Clin. Invest. 57: 1025-1035.

50. Cohen, A., L. J. Gudas, A. J. Ammann, G. E. J. Staal, and D. W. Martin, Jr. 1978. Deoxyguanosine triphosphate as a possible toxic metabolite in purine nucleoside phosphorylase deficiency. J. Clin. Invest. 61: 1405-1409.

51. Shen, L. C., P. L. Fall, G. M. Walton, and D. E. Atkinson. 1968. Interaction between energy charge and metabolite modulation in the regulation of enzymes of amphibolic sequences. Phosphofructokinase and pyruvate dehydrogenase. Biochemistry. 7: 4041-4045.

52. Eilerman, L. J., and E. C. Slater. 1970. The phosphate potential generated by membrane fragments of Azotobacter vinelandii. Biophys. Biochim. Acta. 216: 226-228.

53. Swedes, J. S., R. J. Sedo, and D. E. Atkinson. 1975. Relation of growth and protein synthesis to the adenylate energy charge in an adenine-requiring mutant of Escherichia coli. J. Biol. Chem. 250: 6930-6937.

54. Polmar, S. H., E. M. Wetzler, and R. C. Stern. 1977. Immunopharmacologic studies of adenosine deaminase deficient lymphocytes. Pediatr. Res. 11: 492. (Abstr.)

55. Ballet, J., R. Insel, E. Merler, and F. S. Rosen. 1976. Inhibition of maturation of human precursor lymphocytes by coformycin, an inhibitor of the enzyme adenosine deaminase. J. Exp. Med. 143: 1271-1276.

56. Jenkins, T., A. R. Rabson, G. T. Nurse, A. B. Lane, and D. A. Hopkinson. 1976. Deficiency of adenosine deaminase not associated with severe combined immunodeficiency. J. Pediatr. 89: 732-736.

57. Kaukel, E., U. Fuhrmann, and H. Hilz. 1972. Divergent action of CAMP and dibutyryl cA.MP on macromolecular synthesis in Hela S3 cultures. Biochem. Biophys. Res. Commun. 48: 1516-1524.

58. Hilz, H., and E. Kaukel. 1973. Divergent action mechanism of CAMP and dibutyryl cA.MP on cell proliferation and macromolecular synthesis in Hela S3 cultures. Mol. Cell Biochem. 1: 229-239.

59. Ullman, B., A. Cohen, and D. W. Martin, Jr. 1976. Characterization of a cell culture model for the study of adenosine deaminase- and purine nucleoside phosphorylase-deficient immunologic disease. Cell. 9: 205-211.

60. Kredich, N. M., and D. W. Martin, Jr. 1977. Role of S-adenosylhomocysteine in adenosine-mediated toxicity in cultured mouse T lymphoma cells. Cell. 12: 931-938.

61. Hershfield, M. S., F. F. Snyder, and J. E. Seegmiller. 1977. Adenine and adenosine are toxic to human lymphoblast mutants defective in purine salvage enzymes. Science (Wash. D. C.). 197: 1284-1287.

62. Schwartz, A. L., R. C. Stern, and S. H. Polmar. 1978. Demonstration of an adenosine receptor on human lymphocytes in vitro and its possible role in the adenosine deaminase-deficient form of severe immunodeficiency. Clin. Immunol. Immunopathol. 9: 499-505.

63. Marone, G., M. Plant, and L. M. Lichtenstein. 1978. Characterization of a specific adenosine receptor on human lymphocytes. J. Immunol. 11: 2153-2159. 